\title{
PRIMARY OVARIAN PREGNANCY: A CASE REPORT
}

\author{
J. Y. L. GOH \\ S. P. RACHAGAN \\ E. C. LOW
}

\section{SUMMARY}

A case of an ovarian ectopic pregnancy is presented. The diagnosis was made at laparotomy. Histology of the surgical specimen confirmed a primary ovarian pregnancy. The aetiologic factors and diagnostic criteria are discussed.

\section{INTRODUCTION}

The most common site of an ectopic pregnancy is the ampullary portion of the fallopian tube. However ovarian pregnancies are rare. The first case of an ovarian pregnancy was reported by Saint Maurice de Ferigod in France in 1682. Since then, about 300 cases have been reported in the world literature. We present here a case of a primary ovarian pregnancy.

\section{CASE HISTORY}

The patient, a 31-year-old Indian female, a Para 4, presented at eight weeks gestation with per vaginal bleeding and right iliac fossa pain. There was no history of previous pelvic infection or surgery.

On examination, there was mild pallor. The blood pressure was $120 / 80 \mathrm{mmHg}$ and the pulse rate was $88 / \mathrm{min}$. There was no abnormality detected in the cardiovascular or respiratory systems.

J.Y.L. Goh, MBBS, MRCOG

S.P. Rachagan, MBBS, AM, MRCOG, FACS

Department of Obstetrics \& Gynaecology

E.C. Low, MBBS, MPath

Department of Pathology

Faculty of Medicine

University of Malaya

59100 Kuala Lumpur
The abdomen was tender with mild guarding. Vaginal examination revealed a positive cervical excitation test. The uterus was bulky and deviated to the left. A right tender pulsatile adnexal mass of size $4 \mathrm{~cm} \times 4 \mathrm{~cm}$ was felt. The urine pregnancy test was positive. A clinical diagnosis of a right ectopic pregnancy was made.

The findings at laparotomy revealed a right ovarian pregnancy measuring $6 \mathrm{~cm} \times 6 \mathrm{~cm}$ which was soft and haemorrhagic. There was blood noted leaking from it and approximately $200 \mathrm{ml}$ of blood was noted collected in the pouch of Douglas. The rest of the pelvic organs were normal. Ovarian wedge resection and bilateral tubal ligation were performed.

The post-operative recovery was uneventful and she was discharged on the seventh postoperative day.

\section{Gross Pathology}

The right ovarian mass weighed $40 \mathrm{~g}$ and measured $4.5 \times 4 \times 3.5 \mathrm{~cm}$. The surface was bluish, nodular and smooth except for the site of attachment to the ovarian ligament. No perforation was seen. An ovoid cystic space $2 \times 1.7 \times$ $1.5 \mathrm{~cm}$ was seen within, slightly eccentrically placed, lined by a thin whitish membrane and containing a whitish embryo measuring $0.3 \times 0.2$ $x 0.1 \mathrm{~cm}$ (Fig. 1). The cut surface of the ovarian mass was otherwise haemorrhagic except for a thin peripheral rim of grevish fibrous tissue of uneven thickness.

\section{Histology}

Multiple sections were taken at various sites of the ovarian mass including the cyst and the wall of the mass. Trophoblastic tissue and chorionic 


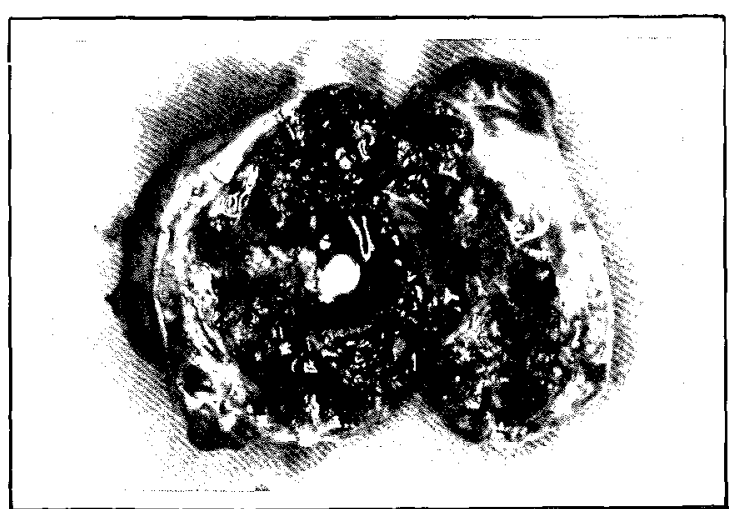

Fig. 1 Primary ovarian pregnancy: the gestation sac is seen within the substance of the ovary.

villi were seen lining the wall of the cystic space and invading into the surrounding haemorrhagic tissue. In places, a gestational sac membrane could be demonstrated. No residual tissue was present. Ovarian tissue could be demonstrated in the non-haemorrhagic parts in which groups of luteinised cells, several primordial follicles and few developing graffian follicles were seen. Histology of the segments of right and left fallopian tubes was normal.

\section{DISCUSSION}

Primary ovarian pregnancy is a rare occurrence. Grimes, based on hospital studies, quoted an incidence of 1 in 7,000 to 10,000 deliveries, which contributed to $2 \%$ of all ectopic pregnancies. ${ }^{1}$ Although occasional cases of live infants have been reported in the world literature, foetal viability is seldom compatible with ovarian pregnancies. ${ }^{2}$

Fifty percent of ovarian pregnancies have identifiable predisposing factors such as pelvic inflammatory disease, pelvic surgery, pelvic endometriosis and the use of the mini-pill. None of these were noted in our patient.
The differentiation between primary and secondary ovarian pregnancy is histological. The diagnostic criteria of primary ovarian pregnancy as laid down by Spiegelberg ${ }^{3}$ in 1873 are as follows:

- The fallopian tube must be intact and clearly separated from the ovary.

- The gestation sac must occupy the normal position of the ovary.

- The gestation sac must be connected to the uterus by the ovarian ligament.

- Ovarian tissue must be demonstrated in the wall of the sac.

The above diagnostic criteria were satisfied in the case presented.

The difficulty in making a firm diagnosis of primary ovarian pregnancy at laparotomy is due to the more common occurrence of abortion onto the ovary from a primary tubal pregnancy. However the management is not altered. In a young patient, the most conservative surgery in the form of ovarian wedge resection or ovarian cystectomy is recommended. In our patient, a bilateral tubal ligation was done in addition as the couple did not wish to have any more children.

\section{REFERENCES}

1 Grimes HG, Nosal RA, Gallagher JC. Ovarian pregnancy: A series of 24 cases. Obstet Gynaecol 1983; $61: 174-180$.

2 William PC, Malvar TC, Kraft JR. Term pregnancy with delivery of a live female infant. Am J Obstet Gynaecol 1982; 142 : 589-591.

${ }^{3}$ Spiegelberg $O$. Zur, Kasuistik der ovarial-schewangenschaft. Arch Gynako/ 1878; $13: 73$. 